\title{
Attentional and emotional mechanisms of pain processing and their related factors: A structural equations approach
}

\author{
Claudia Huber $\mathrm{MSc}^{1,2}$, Miriam Kunz $\mathrm{PhD}^{1}$, Cordula Artelt $\mathrm{PhD}^{3}$, Stefan Lautenbacher $\mathrm{PhD}^{1}$
}

\author{
C Huber, M Kunz, C Artelt, S Lautenbacher. Attentional and \\ emotional mechanisms of pain processing and their related factors: \\ A structural equations approach. Pain Res Manage 2010;15(4):229. \\ 237.
}

BACKGROUND/OBJECTIVE: It is known that maladaptive attentional and emotional mechanisms of pain processing - as indicated by constructs such as pain hypervigilance, pain-related anxiety and pain catastrophizing - play an important role in the development and maintenance of chronic pain conditions. However, little is known to date about the potential risk factors for these forms of maladaptive processing. The aim of the present study was to shed more light on this issue. A very comprehensive set of predictor variables was examined in healthy pain-free subjects. METHOD: Participants were 92 young and healthy subjects (mean [ $\mathrm{SD}]$ age $26.99 \pm 6.90$ years; 47 men, 45 women). Maladaptive attentional and emotional mechanisms of pain processing were assessed by self-report measures of pain hypervigilance, pain-related anxiety and pain catastrophizing, as well as by a dot-probe task. The comprehensive set of predictor variables included measures of affective and bodily distress (depression, anxiety and somatization), experimental pain sensitivity, and cortisol reactivity. Directed relationships were estimated by using structural equation modelling.

RESULTS: Structural equation modelling revealed a significant path from affective and bodily distress to self-reported maladaptive attentional and emotional pain processing. In contrast, the paths from pain sensitivity and cortisol reactivity did not reach the level of significance.

CONCLUSION: These results support the position that anxiety and depression, as well as somatization, contribute to the aberrance of attentional and emotional mechanisms of pain processing. Surprisingly, the assumption of a close relationship between these maladaptive mechanisms of pain processing and pain sensitivity could not be confirmed.

Key Words: Dot-probe task; Pain catastrophizing; Pain hypervigilance; Painrelated anxiety

$\mathrm{P}$ ain hypervigilance, pain-related anxiety and pain catastrophizing have been found to be strongly intercorrelated constructs (1-7), and are all part of contemporary fear avoidance models of chronic pain (see Vlaeyen and Linton [8] for a review). According to this cognitive-affective model (9), these three constructs all refer to attentional and emotional processes, through which certain individuals focus exclusively on as well as exaggerate the threat value of pain or painrelated stimuli. The attentional bias and negative emotional processing might predispose these individuals to develop or maintain chronic pain (10). However, little research to date has aimed to identify potentially related factors involved in the development of this maladaptive psychological processing of pain-related information. Why do some individuals tend to

\section{Mécanismes attentionnels et émotionnels du traitement de la douleur et facteurs connexes : Approche par équations structurales}

\begin{abstract}
HISTORIQUE/OBJECTIFS : On sait que certains mécanismes attentionnels et émotionnels mésadaptés du traitement de la douleur jouent un rôle important dans le développement et la persistance des maladies douloureuses chroniques, comme en témoignent les construits de type hypervigilance, anxiété ou catastrophisme liés à la douleur. Or, on en sait encore relativement peu sur les facteurs de risque potentiels à l'égard de ces processus mésadaptés. Le but de la présente étude était de faire la lumière sur cette problématique. Un ensemble très complet de variables prédictives ont été examinées chez des sujets en bonne santé, libres de toute douleur. MÉTHODES : Au nombre de 92, les participants étaient jeunes et en bonne santé (âge moyen [ \pm É.-T.] 26,99 \pm 6,90 ans; 47 hommes et 45 femmes). Les mécanismes attentionnels et émotionnels mésadaptés du traitement de la douleur ont été évalués au moyen de plusieurs outils d'automesure de l'hypervigilance, de l'anxiété et du catastrophisme liés à la douleur, de même que par un sondage attentionnel (dot-probe). La série complète des variables prédictives incluait des mesures de la détresse affective et physique (dépression, anxiété et somatisation), de la sensibilité à la douleur expérimentale et de la réactivité du cortisol. Les liens dirigés ont été estimés au moyen d'un modèle d'équations structurales.

RÉSULTATS : Le modèle d'équations structurales a révélé un lien significatif entre la détresse affective et physique et un traitement attentionnel et émotionnel mésadapté de la douleur. En revanche, les liens entre sensibilité à la douleur et réactivité du cortisol n'ont pas atteint une portée significative.

CONCLUSIONS : Ces résultats appuient la notion selon laquelle l'anxiété et la dépression, de même que la somatisation contribuent aux anomalies des mécanismes attentionnels et émotionnels du traitement de la douleur. Étonnamment, il a été impossible de confirmer l'hypothèse d'un lien étroit entre ces mécanismes mésadaptés du traitement de la douleur et la sensibilité à la douleur.
\end{abstract}

show maladaptive processing of pain, whereas others do not? The aim of the present study was to examine which potential related factors play a role in maladaptive pain processing.

We started with three potential factors that we assumed to be relevant for the explanation of maladaptive forms of psychological pain processing: affective and bodily distress (depression, anxiety and somatization), experimental pain sensitivity, and regulation of stress hormones; ie, cortisol reactivity. We tested the explanatory power of these candidates using a structural equations approach.

Affective and bodily distress as a related factor The relationship between 'affective and bodily distress' and 'maladaptive mechanisms of pain processing' (pain hypervigilance,

${ }^{1}$ Physiological Psychology, Otto-Friedrich University Bamberg, Bamberg; ${ }^{2}$ Department of Anaesthesiology, Friedrich-Alexander University Hospital

Erlangen, Erlangen; ${ }^{3}$ Empirical Education Research, Otto-Friedrich University Bamberg, Bamberg, Germany

Correspondence: Ms Claudia Huber, Physiological Psychology, Otto-Friedrich University Bamberg, Markuspl 3, Bamberg 96045, Germany.

Telephone 49-0-951-863-18-50, fax 49-0-951-863-1976, e-mail claudia.huber@uni-bamberg.de 
pain catastrophizing and pain-related anxiety) has been demonstrated in several studies. More precisely, Goubert et al (11) conducted a structural equation analysis in chronic pain patients, which revealed that neuroticism can be considered a risk factor for pain hypervigilance, with pain catastrophizing and fear of movement mediating the relationship. Furthermore, associations between depressive mood and pain catastrophizing have also been shown in several studies (12-15). Additionally, Sullivan et al (16) reported that anxiety predicted pain catastrophizing in healthy subjects. Moreover, significant positive correlations between pain-related anxiety and negative affect in chronic pain patients have also been reported (17). Other than these indicators of affective distress (depression and anxiety), it is also of interest to investigate the role of bodily distress (somatization) as a related factor. This seems rational for two reasons. First, somatization - similar to depression and anxiety - has also been shown to be associated with maladaptive mechanisms of pain processing (18-20). To be more precise, in the signal-filtering model (18) of somatization, it is assumed that due to deficits in neural filtering processes, bodily signals that are normally filtered out come to consciousness, resulting in a vicious circle of heightened attention toward pain-related stimuli and somatization. Second, there seems to be a close link between the two constructs 'affective distress' and 'somatization', which has already been pointed out in a recent review by Lieb et al (21). These considerations were reasons enough to assume that affective and bodily distress are of influence in determining how an individual attentionally and emotionally handles pain-related information.

\section{Pain sensitivity as a related factor}

Highly pain-sensitive individuals experience day-to-day pain more often and more intensely than less sensitive subjects because even objectively weak noxious stimulation can lead to activation of the pain system. This might be explained, in part, by physiological factors such as genetics, endocrinology and brain anatomy. As a consequence of these more frequent and intense painful experiences, these individuals may develop attentional and emotional habits of pain processing, biased toward early detection and the most efficient avoidance of pain. Associations between experimental pain sensitivity and such forms of maladaptive pain processing have already been examined and confirmed in several studies. In particular, pain hypervigilance proved to be associated with heightened pain sensitivity $(22,23)$. However, the direction of this association is still under debate, with some authors arguing that having excessive concerns with pain predicts pain sensitivity in healthy subjects (24-26), and with others arguing, in line with the authors of the present study, that heightened pain sensitivity predicts pain catastrophizing and pain hypervigilance (27,28).

\section{Cortisol reactivity as a related factor}

Associations between processing of threat-related stimuli and hypothalamic-pituitary-adrenal (HPA) functioning have been found in several studies (29-31). Although chronically elevated HPA activity has often been associated with negative emotions such as depression, findings of acute fear reduction after a single glucocorticoid administration support the idea that an acute increase in cortisol levels might be related to fearreducing and anxiety-protective effects (32-34). The data of
Putman et al (32) were the first to show that preconscious attention to fear is directly influenced by cortisol, suggesting possible involvement of this mechanism in the development and maintenance of anxiety disorders. We applied this idea to the genesis of maladaptive psychological mechanisms of pain processing. Thus, restricted cortisol reactivity is supposed to accompany a lack of regulatory control over attentional and emotional pain processing, eventually constituting a further predisposing factor. To our knowledge, this hypothesis has not yet been tested.

\section{Assessing attentional and emotional mechanisms of pain processing}

The maladaptive attentional and emotional mechanisms of pain processing were assessed using self-report questionnaires (Pain Vigilance and Awareness Questionnaire [PVAQ; 35], Pain Anxiety Symptoms Scale [PASS; 36] and Pain Catastrophizing Scale [PCS; 37]) as well as by behavioural measures (dot-probe task). These variables were deliberately assessed before experimental pain testing to guarantee that the individual would expect a pain experience in the near future, which may have activated this type of pain processing.

In summary, the novel aspect of the present study was to use a very comprehensive approach to investigate which factors help to explain the occurrence of maladaptive psychological mechanisms of pain processing. More precisely, we tried to answer the following question: Do heightened affective and bodily distress, heightened pain sensitivity and reduced cortisol reactivity contribute to the aberrance of attentional and emotional mechanisms of pain processing in healthy pain-free subjects? To investigate this question, we designed and tested a structural equation model (SEM). Direct paths from the designated predisposing factors (without significant interactions among them) to the criterion variable 'attentional and emotional mechanisms of pain processing' were expected to be significant. Being aware of the restrictions arising from a crosssectional approach, we were mainly interested in finding first evidence supporting the presumed model.

\section{Subjects}

\section{METHODS}

Subjects were recruited from the student population of the Otto-Friedrich-University Bamberg (Bamberg, Germany) and from volunteers who responded to advertisements posted in public buildings across town. After the exclusion of 16 subjects because of chronic pain conditions (eg, chronic headache and chronic low back pain), previous surgical interventions or psychological disorders (current or previous), 92 young and healthy subjects between 18 and 40 years of age (mean $[ \pm S D]$ age $27.0 \pm 6.9$ years) participated in the present study. The group consisted of 47 men and 45 women. Twentysix of the female subjects were taking oral contraceptives. Of the women not taking oral contraceptives, eight participated while in the first one-third of their natural menstrual cycle (days 1 to 9), five participated while in the second one-third (days 10 to 18) and six participated while in the last one-third (days 19 to 28). This scheduling of sessions allowed for control of potential menstrual cycle effects, which are likely to occur in the case of pain parameters (38-40). Distinct effects of oral contraceptives or menstrual cycles have not been reported for 
TABLE 1

Descriptive statistics of all indicator variables, sorted in accordance with the appropriate latent variables in the structural equation model

\begin{tabular}{|c|c|c|}
\hline Latent variables & Indicator variables & Mean \pm SD \\
\hline \multirow[t]{4}{*}{ Psychological mechanisms of pain processing } & Dot-probe pain-related words (index score) & $-0.12 \pm 40.18$ \\
\hline & PVAQ (sum score) & $33.32 \pm 12.31$ \\
\hline & PCS (sum score) & $14.23 \pm 7.72$ \\
\hline & PASS (sum score) & $71.84 \pm 26.39$ \\
\hline \multirow[t]{4}{*}{ Pain sensitivity } & Pressure pain threshold, $\mathrm{kPa}$ & $313.31 \pm 120.90$ \\
\hline & Cold pain threshold, ${ }^{\circ} \mathrm{C}$ & $13.20 \pm 7.78$ \\
\hline & Heat pain threshold, ${ }^{\circ} \mathrm{C}$ & $44.61 \pm 2.33$ \\
\hline & Temporal summation of heat pain (rating scale) & $-0.59 \pm 1.40$ \\
\hline \multirow[t]{3}{*}{ Affective and bodily distress } & SOMS (somatization severity index) & $0.15 \pm 0.19$ \\
\hline & STAI-X1 (sum score) & $33.56 \pm 7.10$ \\
\hline & CES-D (sum score) & $10.17 \pm 7.24$ \\
\hline \multirow[t]{2}{*}{ Cortisol reactivity } & Morning cortisol, $\mathrm{nmol} / \mathrm{L} \cdot \min$ & $1117.08 \pm 396.61$ \\
\hline & Cortisol suppression $\mathrm{nmol} / \mathrm{L} \cdot \min$ & $547.58 \pm 376.24$ \\
\hline
\end{tabular}

CES-D Center for Epidemiological Studies Depression Scale; PASS Pain Anxiety Symptoms Scale; PCS Pain Catastrophizing Scale; PVAQ Pain Vigilance and Awareness Questionnaire; SOMS Screening for Somatoform Symptoms; STAI-X1 State-Trait Anxiety Inventory (State Anxiety)

the other parameters investigated in the present study (41-44).

The study protocol was approved by the ethics committee of the medical faculty of the Friedrich-Alexander University Erlangen-Nürnberg (Erlangen, Germany). All participants gave written informed consent. Except for the students, who received course credit as compensation for their efforts, all subjects were paid for participation.

\section{Materials and procedure \\ Operationalization of variables: First, latent variables and indicator variables were defined to prepare the SEM. The latent variables were believed to underlie the indicator vari- ables. Table 1 presents an overview of all the latent and indica- tor variables.}

Assessment of variables:

Assessment of attentional and emotional mechanisms of pain processing:

Self-report questionnaires: Attentional and emotional mechanisms of pain processing, of which individuals are principally aware, were assessed by self-report questionnaires (German versions) for pain hypervigilance (PVAQ) (35), pain-related anxiety (PASS) (36) and pain catastrophizing (PCS) (37).

The PVAQ (35) was developed as a comprehensive measure of attention to pain, and has been validated for use in chronic pain and nonclinical samples (45). It consists of 16 items (eg, 'I am quick to notice changes in pain intensity') that are rated on a six-point scale, and that assess awareness, vigilance, preoccupation and observation of pain. For further analyses, the combined sum score of the PVAQ was used as advised in the literature (35). PVAQ total scores range from 0 to 80.

The PASS (36) is composed of four subscales - cognitive anxiety, escape/avoidance, fearful appraisal and physiological anxiety - and is designed to measure pain anxiety across cognitive, behavioural and physiological domains. The items (eg, 'When I feel pain I am afraid that something terrible will happen') are rated on a six-point scale. For further analyses, the combined sum score ( 40 items) of the PASS was used as recommended by other authors $(36,46)$. PASS total scores range from 0 to 240 .

The PCS (37) was developed as a measure of catastrophizing related to pain. It contains 13 items (eg, 'I worry all the time about whether the pain will end') that can be divided into three subscales - rumination, magnification and helplessness. The items are rated on a five-point scale. For further analyses, the combined sum score of the PCS was used as has usually been done in preceding studies $(37,47)$. PCS total scores range from 0 to 52. According to the user manual, a total PCS score of 30 represents a clinically relevant level of catastrophizing.

All questionnaires had been submitted - either by Walter et al (PASS) (46) or by the authors of the present study - to a forward-backward translation procedure, which means that the German translations were in turn translated by an English native speaker (with German as his second language) back to English. Translations were improved until the original English versions and the final English versions were sufficiently similar. The intercorrelations of the three German questionnaires administered to native Germans ranged between $r=0.47$ and $\mathrm{r}=0.76$, which is in accordance with intercorrelations reported in the literature for English and Dutch versions administered to native English and Dutch speakers, respectively (1-4,48). Cronbach's alpha coefficients ranged from 0.86 to 0.94 for the original English versions and from 0.87 to 0.93 for the German versions. According to these results, the English and German versions appeared to be sufficiently similar.

Dot-probe task: A selective attention task was used for painrelated stimuli based on the dot-probe task described by Keogh et al (49). It contains three emotional word categories: painrelated (eg, stechend/stinging), social threat (eg, beschämt/ ashamed) and positive words (eg, glücklich/lucky). A fourth category of neutral words (anstrich/paintwork) was added. The words of the original version by Keogh et al (49) were translated into German. Because not all words in German fulfilled the criteria of being similar in length and frequency of use, some words had to be replaced. A new list was composed, containing 456 words, which were more than necessary. Twenty-six volunteers (13 male and 13 female students from Otto-Friedrich University Bamberg, none of whom were currently in pain) were instructed to classify the words into one of the abovementioned categories to test whether the words were representative of the designated word category. If the words were not classified unambiguously into categories, they were excluded from use in the dot-probe task. The final version 
contained the 256 best-fitting words ( 32 trials per category). During screen presentation, the emotional words were paired with neutral words; neutral-neutral word pairs served as filler items. For each word category, 32 pairs of words were generated.

Following the method of Keogh et al (49), a fixation cross was first presented in the centre of a computer screen for 500 ms. Next, two words (a neutral one paired with an emotional one) were presented concurrently, one below and one above the centre. After another $500 \mathrm{~ms}$, words were removed and a dot appeared in the location of one of the words. Subjects were required to indicate via a key press as quickly as possible where the dot appeared relative to the centre of the screen (below or above). A reaction time measurement was taken. After 20 practice trials, participants had to complete 128 test trials ( 32 trials per word-pair category), all of which were presented in random order by the computer. Bias indexes were calculated on the basis of reaction times to separately assess the attentional bias toward each emotional word category (49). A positive score indicated an attentional preference for the location of the emotional word, which suggested vigilance, whereas a negative score suggested avoidance. In the present report, only the attentional bias for pain words was considered.

Additionally, participants completed a word comprehension task (Intelligence Structure Test 2000 R, Form A) (50) as well as a reading task (analogous to the dot-probe task, word pairs of real and nonsense words were presented on a computer screen for $500 \mathrm{~ms}$ and subjects had to indicate by key press where the real word appeared) to ensure the participants' capacity to read and understand words quickly enough. Subjects with results poorer than 1.5 SDs below the mean in the word comprehension task would have been excluded from analysis, as well as those with more than 15 missing or false values in the reading task. However, none of the 92 subjects had to be excluded.

Assessment of pain sensitivity: The latent variable pain sensitivity was assessed through the measurement of pressure pain threshold, cold pain threshold, heat pain threshold and temporal summation of heat pain. All subjects were trained until they understood all procedures and were able to follow the instructions before testing. The assessments of pain thresholds and temporal summation were the same as described by Lautenbacher et al (51).

Pressure pain threshold: The assessment of pressure pain threshold was performed using a hand-held pressure algometer (Algometer type II, Somedic Sales AB, Sweden) with a probe area of $1 \mathrm{~cm}^{2}$. The site of stimulation was the volar surface of the right forearm. The pressure was increased from $0 \mathrm{kPa}$ at a rate of $50 \mathrm{kPa} / \mathrm{s}$ until the subject felt the first pain sensation and pressed a button. There were five trials and the threshold was determined as the average of these trials.

Cold and heat pain thresholds: Thermal stimuli were delivered by use of a Peltier-based, computerized thermal stimulator (Medoc TSA-2001; Medoc Ltd, Israel) with a $3 \mathrm{~cm} \times 3 \mathrm{~cm}$ contact probe. The site of stimulation was the volar surface of the left forearm, where the contact thermode was attached. For assessment of cold and heat pain thresholds, thermode temperature started from a baseline of $32^{\circ} \mathrm{C}$ and was increased or decreased at a rate of $1^{\circ} \mathrm{C} / \mathrm{s}$ until the subjects felt a first pain sensation and responded by pressing a button. The temperature was then returned to baseline and held constant until the next trial.
There were five trials each of heat and cold stimulation, and the pain thresholds were determined as the average of the five trials.

Temporal summation: For assessment of temporal summation, a series of 10 stimuli was applied with an interstimulus interval of $2.5 \mathrm{~s}(0.4 \mathrm{~Hz})$ to the volar site of the left forearm. Temporal summation was tested by comparing the sensations evoked by single pulses (assessed first) to sensations evoked by a series of 10 pulses (only the last pulse was rated) that was delivered $60 \mathrm{~s}$ later. Subjects rated the sensations on a numerical rating scale $(0$ to 10, labelled with verbal anchors 'no pain' to 'strongest pain imaginable'). The stimuli were presented relative to the individual heat pain thresholds $\left(3^{\circ} \mathrm{C}\right.$ above the threshold). The heat pain stimuli (saw-tooth shape) started at a baseline temperature of $3^{\circ} \mathrm{C}$ below the individual pain threshold and increased with a heating rate of $4^{\circ} \mathrm{C} / \mathrm{s}$. Three runs were performed. Temporal summation was determined as the averaged difference between sensations evoked by single stimuli and series of stimuli.

Assessment of affective and bodily distress: The latent variable 'affective and bodily distress' was indicated by three selfrating scales, namely the German version of the Screening for Somatoform Symptoms (SOMS) (52), the German version of the State-Trait Anxiety Inventory (State Anxiety) (STAI-X1) (53) and the Center for Epidemiologic Studies Depression Scale (CES-D; German version: Allgemeine Depressionsskala) (54).

The SOMS (52) is a self-rating scale that assesses 53 organically unexplained physical symptoms (eg, headache, low back pain and nausea). The state version of the SOMS was applied, in which subjects were asked to rate the intensity of each symptom and the extent of interference with well-being during the previous seven days on a five-point Likert scale. For further analyses, the mean of all items was used ('somatization severity index'). The somatization severity index ranges from 0 to 4 .

The STAI-X1 (53) is a self-rating scale and contains 20 items that were designed to measure transitory anxiety states - that is, subjective feelings of apprehension, tension and worry that vary in intensity and fluctuate based on the situation. Items are rated on a five-point rating scale. The STAI-X1 total score ranges from 20 to 80 .

The CES-D (54) is a self-rating scale that was designed to assess emotional, somatic and cognitive symptoms of depressive mood during the previous week. It contains 20 items that are rated on a four-point Likert scale. The CES-D total score ranges from 0 to 60 . A total score of 23 represents a clinically relevant level of depression.

Cronbach's alpha coefficients ranged from 0.87 to 0.91 according to reports of the questionnaires developers and from 0.87 to 0.90 in the present study.

Assessment of cortisol reactivity: Free cortisol levels after awakening are considered to be a reliable biological marker for adrenocortical activity when measured repeatedly with reference to the time of awakening (55). The validity and reliability of the dexamethasone (DEX) suppression test for assessing the feedback sensitivity of the HPA axis have been proven in several studies $(56,57)$. Assessment of cortisol has meanwhile become standard in psychological experiments. Following the protocol of Pruessner et al (58), subjects were asked to provide a sample of their saliva at the time of awakening, and $15 \mathrm{~min}$, $30 \mathrm{~min}, 45 \mathrm{~min}$ and $60 \mathrm{~min}$ thereafter for two consecutive days 


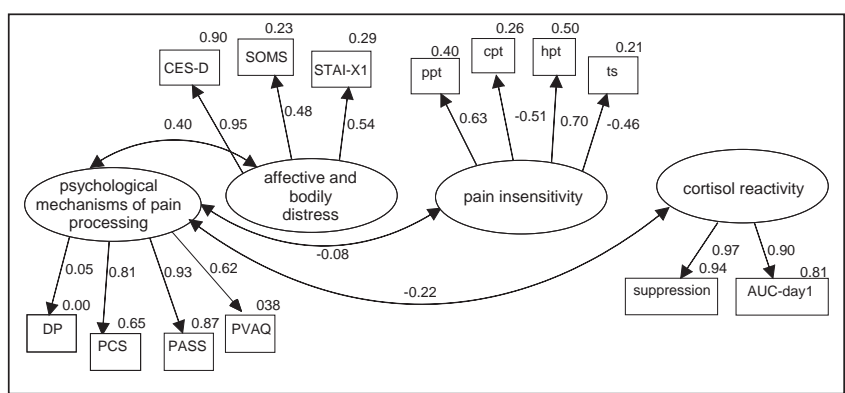

Figure 1) Examination of the measurement model by confirmatory factor analysis. Factor loadings (presented next to the single-headed arrows) and correlation coefficients (presented next to the doubleheaded arrows) are shown. AUC Area under the cortisol at the time of awakening response curve; CES-D Center for Epidemiologic Studies Depression Scale; cpt Cold pain threshold; DP Dot-probe (pain words); hpt Heat pain threshold; PASS Pain Anxiety Symptoms Scale; PCS Pain Catastrophizing Scale; ppt Pressure pain threshold; PVAQ Pain Vigilance and Awareness Questionnaire; SOMS Screening for Somatoform Symptoms; STAI-X1 State-Trait Anxiety Inventory (State Anxiety); ts Temporal summation of heat pain

before the experimental session. Subjects were required to expectorate $0.5 \mathrm{~mL}$ to $1.0 \mathrm{~mL}$ of saliva into a plastic vial through a short plastic straw (DRG Instruments $\mathrm{GmbH}$, Germany). At 23:00 on the first day, the participants ingested a tablet of $0.5 \mathrm{mg}$ DEX (Merck, Germany). This was performed to assess the extent of cortisol suppression produced by a small dose of DEX (Mini Dexamethasone Suppression Test) (58). For verification purposes, subjects were required to complete a collection protocol in which they had to document the exact times of collection, starting with the time of awakening. Additionally, they had to give a short description of their activity at the collection time. To obtain valid data, the importance of precisely following and documenting the cortisol collection times and refraining from eating and brushing their teeth before saliva collection was explained in great detail to the subjects. Moreover, the cortisol data were also checked for plausibility later on. Subjects stored saliva samples at home in their freezer and brought them to the session. They were stored in a $-20^{\circ} \mathrm{C}$ freezer until further analyses were performed. Salivary cortisol was assayed using an ELISA kit (DRG Instruments, Germany). The intra-assay coefficient of variation was less than $5.5 \%$ and the corresponding interassay coefficient was less than $6.5 \%$. The analytical sensitivity was $1.48 \mathrm{nmol} / \mathrm{L}$. The competitive immunoassay requires $1.5 \mathrm{~h}$ of incubation time, and has demonstrated a robust and reproducible performance. To quantify cortisol reactivity, two indicators were computed for further analyses: morning cortisol increase during the first hour after waking (area under the cortisol awakening response curve up to 60 min after waking on day 1) and cortisol suppression after DEX (difference between area under the awakening response curve of day 1 and day 2).

\section{Procedure}

The sessions took place between 15:00 and 19:00, and lasted for approximately $2 \mathrm{~h} 15 \mathrm{~min}$ each. It included the following tests run in the given order: a screening for psychological disorders using a standardized psychological interview (Mini-DIPS) (59); assessment of variables targeting the attentional and emotional
TABLE 2

Fit indexes of the confirmatory factor analysis (CFA) estimations calculated using the maximum likelihood method

\begin{tabular}{lccccc}
\hline CFA & $\chi^{2}$ Idf & GFI & AGFI & CFI & RMSEA \\
\hline CFA including all variables & 1.22 & 0.90 & 0.83 & 0.93 & 0.05 \\
$\begin{array}{l}\text { CFA after exclusion of the bias } \\
\text { index of the dot-probe task }\end{array}$ & 1.25 & 0.90 & 0.84 & 0.97 & 0.05 \\
\hline
\end{tabular}

Ideal fit indexes are relative $\chi^{2}\left(\chi^{2} / d f\right) \leq 2.5$; goodness of fit index (GFI), adjusted GFI (AGFI) and comparison fit index (CFI) $\geq 0.9$; and root mean square error of approximation (RMSEA) $\leq 0.05$ (acceptable: RMSEA $\leq 0.08$ )

mechanisms of pain processing (dot-probe task and questionnaires); assessment of pain sensitivity (pain thresholds and temporal summation of heat pain); and assessment of affective and bodily distress (questionnaires). (The Mini-DIPS is a structured interview based on the Diagnostic and Statistical Manual of Mental Disorders, Fourth Edition and International Classification of Diseases, 10th Revision criteria for current [within the past six months] psychological disorders. It assesses the following: anxiety, affective, somatization, obsessive-compulsive, post-traumatic stress, acute stress and eating disorders; alcohol or drug abuse or addiction; and schizophrenic psychoses.) Cortisol reactivity was assessed as described before the session.

\section{Statistical analysis}

Data were statistically analyzed using SPSS version 15.0 (SPSS Inc, USA) for Windows (Microsoft Corp, USA). SEM operations (confirmatory factor analysis [CFA] and path analysis) were performed using analysis of moment structures (Amos 7.0, SPSS Inc) with maximum likelihood estimation. All descriptive statistics are given as means and SDs.

Preliminary data analysis consisted of standardizing variables (z-transformation) and testing for multivariate normality. After that, CFA was used to test whether the grouping of variables was in line with the assumed factors. Finally, the structural integrity of the hypothesized model was tested, which means that the question of how well the hypothesized model fit the empirical data was answered. Calculations of the relationships between the latent variables were based on covariances of the indicator variables after $z$-transformation. In line with the recommendations of Bollen and Long (60), several fit indexes were used to assess model fit (61): relative $\chi^{2}\left(\chi^{2} / \mathrm{df}\right)$ with a cut-off value for good fit of 2.5 or less, goodness of fit index with a cutoff value of 0.90 or greater, adjusted goodness of fit index with a cut-off value of 0.90 or greater, comparative fit index with a cutoff value of 0.90 or greater, and root mean square error of approximation with cut-off values of 0.05 or less for close fit and 0.08 or less for still acceptable fit. Findings were always considered to be statistically significant at $\alpha=0.05$.

\section{Preliminary analysis}

\section{RESULTS}

The descriptive data of all variables assessed are displayed in Table 1 (values before $z$-transformation). CFA was conducted before testing the SEM to examine the measurement model, with intercorrelations between the criterion variable ('psychological mechanisms of pain processing') and the predictor variables ('affective and bodily distress', 'pain sensitivity' and 'cortisol reactivity') (Figure 1). The results showed an acceptable fit of the data (Table 2). All questionnaires, as well as the 


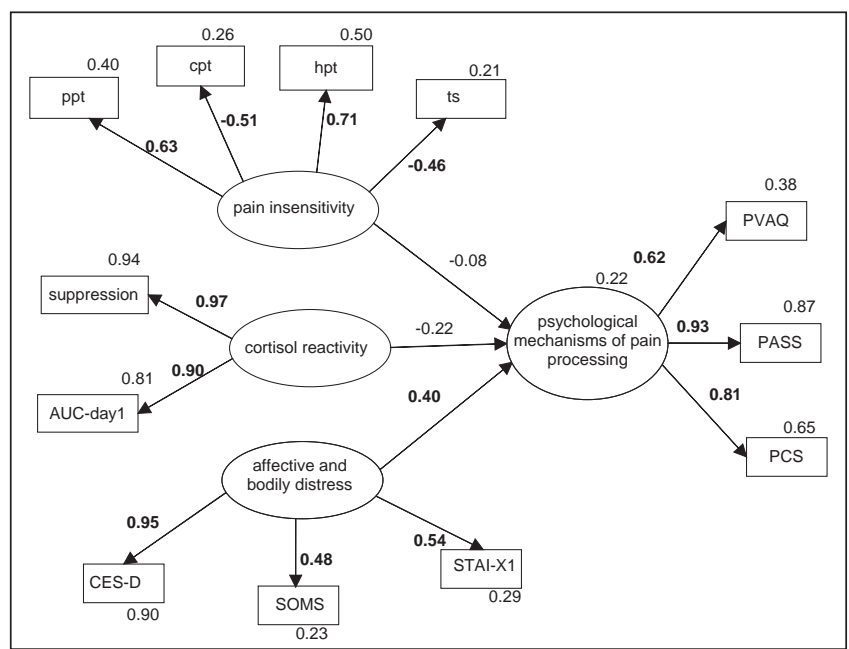

Figure 2) Structural equation model prediction of psychological mechanisms of pain processing by the factors 'affective and bodily distress', 'pain insensitivity' and 'cortisol reactivity'. Standardized beta coefficients (presented next to each pathway) and values of $R^{2}$ (presented next to each indicator variable and predicted variable) are reported. Significant results are marked in bold. AUC Area under the cortisol at the time of awakening response curve; CES-D Center for Epidemiologic Studies Depression Scale; cpt Cold pain threshold; hpt Heat pain threshold; PASS Pain Anxiety Symptoms Scale; PCS Pain Catastrophizing Scale; ppt Pressure pain threshold; PVAQ Pain Vigilance and Awareness, Questionnaire; SOMS Screening for Somatoform Symptoms; STAI-X1 State-Trait Anxiety Inventory (State Anxiety); ts Temporal summation of heat pain

cortisol parameters and the experimental pain parameters, were loaded on the designated latent constructs. This indicated that the latent constructs 'attentional and emotional mechanisms of pain processing', 'affective and bodily distress', 'pain sensitivity' and 'cortisol reactivity' were validly operationalized. The factor 'pain sensitivity' is called 'pain insensitivity' from this point onward because of the positive loadings of the indicator variables pressure pain threshold and heat pain threshold, and the negative loading of cold pain threshold (with reversed numerical direction of scores). However, the bias index for pain words in the dot-probe task was not associated with the results of the self-report PCS, PASS or PVAQ questionnaires. In other words, the attentional bias did not show a significant loading on the latent variable 'psychological mechanisms of pain processing' compared with the questionnaires. Thus, the attentional bias derived from the dot-probe task was excluded from the model. CFA was computed again, now with only the self-report questionnaires included, which again showed an acceptable fit (Table 2).

\section{Model testing}

The model predicting 'attentional and emotional mechanisms of pain processing' by 'affective and bodily distress', 'pain insensitivity' and 'cortisol reactivity' is shown in Figure 2. Four of five fit indexes of this model showed acceptable values, as presented in Table 3. The pathway from 'affective and bodily distress' (best indicated by the CES-D; standardized beta coefficient $=0.95, \mathrm{P}=0.001)$ to 'attentional and emotional mechanisms of pain processing', indicated by the questionnaires
TABLE 3

Fit indexes of the structured equations model estimations calculated using the maximum likelihood method

\begin{tabular}{rcccc}
\hline$\chi^{2} /$ df & GFI & AGFI & CFI & RMSEA \\
\hline 1.246 & 0.895 & 0.839 & 0.965 & 0.052 \\
\hline
\end{tabular}

Ideal fit indexes are relative $\chi^{2}\left(\chi^{2} / d f\right) \leq 2.5$; goodness of fit index (GFI), adjusted GFI (AGFI) and comparison fit index (CFI) $\geq 0.9$; and root mean square error of approximation (RMSEA) $\leq 0.05$ (acceptable: RMSEA $\leq 0.08$ )

TABLE 4

Correlation coefficients $(r)$ between the questionnaires used to assess the latent variables 'psychological mechanisms of pain processing' and 'affective and bodily distress'

\begin{tabular}{|c|c|c|c|c|c|c|}
\hline & \multicolumn{3}{|c|}{$\begin{array}{l}\text { Psychological mechanisms } \\
\text { of pain processing }\end{array}$} & \multicolumn{3}{|c|}{$\begin{array}{l}\text { Affective and } \\
\text { bodily distress }\end{array}$} \\
\hline & PVAQ & PASS & PCS & CES-D & STAI-X1 & SOMS \\
\hline PVAQ & & $0.58^{*}$ & $0.47^{\star}$ & $0.27^{*}$ & 0.02 & $0.25^{\star}$ \\
\hline PASS & & & $0.76^{\star}$ & $0.34^{*}$ & 0.19 & $0.29^{*}$ \\
\hline PCS & & & & $0.34^{*}$ & 0.16 & $0.22^{\star}$ \\
\hline CES-D & & & & & $0.52^{\star}$ & $0.46^{*}$ \\
\hline STAI-X1 & & & & & & $0.21^{*}$ \\
\hline
\end{tabular}

*Significant result. CES-D Center for Epidemiologic Studies Depression Scale; PASS Pain Anxiety Symptoms Scales; PCS Pain Catastrophizing Scale; PVAQ Pain Vigilance and Awareness Questionnaire; SOMS Screening for Somatoform Symptoms; STAI-X1 State-Trait Anxiety Inventory (State Anxiety)

PVAQ, PASS and PCS, was highly significant (standardized beta coefficient $=0.40 ; \mathrm{P}<0.001$ ). However, this was the only significant pathway between the predisposing factors and the criterion variable. Altogether, the model explained $22 \%$ of the variance of the criterion.

To exclude the alternative explanation that this finding is only due to a construct overlap between 'psychological mechanisms of pain processing' and 'affective and bodily distress', correlation analyses between the questionnaires used were conducted. The results are presented in Table 4. As can be seen, the correlations between the questionnaires of the two respective constructs are sufficiently small to exclude vast construct overlap.

\section{DISCUSSION}

The major aim of the present study was to investigate to what extent the constructs 'affective and bodily distress', 'pain sensitivity' and 'cortisol reactivity' contribute to variance of attentional and emotional mechanisms of pain processing (indicated by measures of pain hypervigilance, pain-related anxiety and pain catastrophizing). The main findings produced by the SEM can be summarized as follows: affective and bodily distress - in particular, depressive mood - predicted these maladaptive mechanisms of pain processing significantly; neither cortisol reactivity nor pain sensitivity reached a level of significance; and all hypothesized related factors combined helped to explain $22 \%$ of the criterion variable.

Of note, the criterion variable 'attentional and emotional mechanisms of pain processing' had to be limited to self-report measures to produce these results. The attentional bias index derived from the dot-probe task did not have a relationship with the other indicators of this latent variable. This again corroborates only a loose association between attention and 
vigilance to pain as reflected by self-report and the same concepts when examined with behavioural tests $(28,62-65)$. This divergence represents both a theoretical and an empirical challenge for future research.

As predicted by our model, there was a significant pathway from 'affective and bodily distress' to 'psychological mechanisms of pain processing'. In particular, depressive mood appeared to predispose individuals to increased attention to and more negative emotions about pain. The observed relationship between these two sets of variables in our study and in investigations by other authors (66-70) suggests that depression and maladaptive mechanisms of pain processing are related but, nevertheless, distinct constructs. The latter conclusion can be based on the result that the shared variance of CES-D and PCS in our study did not exceed $11 \%$.

Finding depression to be a related and potentially predisposing factor for maladaptive psychological processing of painrelated stimuli is also in accordance with results from previous studies in chronic pain patients $(11,27,71)$. Adding to that, Janssen (72) recently assumed that negative emotions such as anxiety or anger increase vigilance to the threat value of painrelated stimuli. Altogether, our findings provide corroborative evidence that strongly focused attention to pain and negative emotions about pain are mainly observed in individuals with high levels of affective and bodily distress.

Cortisol reactivity and pain sensitivity missed the level of significance as putative related factors. However, they added to the explanatory power of the factor 'affective and bodily distress'; these three factors combined explained $22 \%$ of variance in the criterion variable 'attentional and emotional mechanisms of pain processing'.

A surprising finding was that experimental pain sensitivity appeared to be largely unrelated to psychological mechanisms of pain processing, at least in the chosen setting. This contradicts our original assumption that high pain sensitivity promotes the development of increased vigilance to pain. Moreover, it contradicts conceptualizations of hypervigilance that are based on the assumption that pain hypervigilance and heightened pain sensitivity are two aspects of the same process $(22,23)$.

\section{Limitations}

There are some limitations of our study that have not yet been mentioned and that suggest the necessity of future research. First, our findings are based on cross-sectional data, which do not allow for assessing the generic relationship between variables; thus, directions of influences remain ambiguous. This shortcoming can be overcome only in longitudinal studies. Second, results of structural equation modelling with small sample sizes must be interpreted very carefully. Usually, sample sizes of at least 100 are recommended (61). Due to some unexpected drop-outs from our sample, we slightly missed this margin. Because our study consumed considerable time and money, we could not easily compensate for that problem. Third, we cannot strictly rule out order effects because we always assessed the psychological mechanisms of pain processing before the actual pain stimuli were applied in our sessions. We did this deliberately to assess the criterion variable in all subjects while they were expecting pain in the near future. Fourth, we cannot exclude that our German versions of the questionnaires and of the words in the dot-probe task did not perfectly converge with the English originals. However, there is no evidence that our versions deviate more than the Dutch versions, which have repeatedly been applied and published with success. Fifth, all participants were volunteers, who were healthy and who responded to advertisements, which might have excluded individuals who, for example, strongly feared the pain they would have incurred from participation; for these reasons, bottom effects (eg, in pain catastrophizing and depression) might have occurred in some analyses with influence on the quality of predictions. Finally, although we tried to assess the related factors of the attentional and emotional mechanisms of pain processing in a very comprehensive way that considered psychological, physiological and psychophysical factors, we were far from being complete in that respect. Future research is required to investigate other pathways of prediction of these maladaptive forms of pain processing. For example, psychosocial aspects as well as developmental aspects might be relevant, as indicated in a recent study by Meredith et al (73), who showed that an insecure adult attachment style is associated with pain catastrophizing.

\section{CONCLUSION}

Our results support the idea that, in healthy individuals, maladaptive psychological processing of pain-related information becomes more likely in a state of heightened affective and bodily distress. Another important finding was that high pain sensitivity did not appear to account for the aberrance in attentional and emotional mechanisms of pain processing. This is not in line with previous conceptualizations of pain hypervigilance $(22,23)$ and might impact further research in this field. The results of our study may also have clinical implications. Maladaptive psychological mechanisms of pain processing, as investigated in the present study, have been assumed to enhance vulnerability to developing chronic pain; eg, after surgery $(51,74)$. Boersma and Linton (75) revealed that the combined appearance of pain-related fear and depressive mood - the co-occurrence of which was also observed in the present study - goes along with frequent health care use (compared with individuals who show high levels in only one of the two variables). Therefore, a parallel strategy of intervention aimed at both affective distress and maladaptive processing of pain-related information appears to be useful.

ACKNOWLEDGEMENTS: This study was supported by a research grant from the Deutsche Forschungsgemeinschaft (La 685/6-2). We thank Julia Förster and Jessica Peter for their support in data collection. We also thank the anonymous reviewers for their extensive advice.

\section{REFERENCES}

1. Burns JW, Glenn B, Bruehl S, Harden RN, Lofland K. Cognitive factors influence outcome following multidisciplinary chronic pain treatment: A replication and extension of a cross-lagged panel analysis. Behav Res Ther 2003;41:1163-82.

2. Moss-Morris R, Humphrey K, Johnson MH, Petrie KJ. Patients' perceptions of their pain condition across a multidisciplinary pain management program: Do they change and if so does it matter? Clin J Pain 2007;23:558-64.

3. Roelofs J, Peters ML, McCracken L, Vlaeyen JW. The pain vigilance and awareness questionnaire (PVAQ): Further psychometric 
evaluation in fibromyalgia and other chronic pain syndromes. Pain 2003;101:299-306.

4. Roelofs J, McCracken L, Peters ML, Crombez G, van Breukelen G, Vlaeyen JW. Psychometric evaluation of the Pain Anxiety Symptoms Scale (PASS) in chronic pain patients. J Behav Med 2004;27:167-83.

5. Vangronsveld K, Van Damme S, Peters M, Vlaeyen J, Goossens M, Crombez G. An experimental investigation on attentional interference by threatening fixations of the neck in patients with chronic whiplash syndrome. Pain 2007;127:121-8.

6. Van Damme S, Crombez G, Eccleston C, Koster EH. Hypervigilance to learned pain signals: A componential analysis. J Pain 2006;7:346-57.

7. Peters ML, Vlaeyen JW, Kunnen AM. Is pain-related fear a predictor of somatosensory hypervigilance in chronic low back pain patients? Behav Res Ther 2002;40:85-103.

8. Vlaeyen JWS, Linton SJ. Fear-avoidance and its consequences in chronic musculoskeletal pain: A state of the art. Pain 2000;85:317-32.

9. Eccleston C, Crombez G. Pain demands attention: A cognitive-affective model of the interruptive function of pain. Psychol Bull 1999;125:356-66.

10. Asmundson GJG, Norton PJ, Vlaeyen JWS. Fear-avoidance models of chronic pain: An overview. In: Asmundson GJG, Vlaeyen JWS, Crombez G, eds. Understanding and Treating the Fear of Pain. Oxford: Oxford University Press, 2004:3-24.

11. Goubert L, Crombez G, Van Damme S. The role of neuroticism, pain catastrophizing and pain-related fear in vigilance to pain: A structural equations approach. Pain 2004;107:234-41.

12. Turner JA, Mancl L, Aaron LA. Pain-related catastrophizing: A daily process study. Pain 2004;110:103-11.

13. Meyer K, Tschopp A, Sprott H, Mannion AF. Association between catastrophizing and self-rated pain and disability in patients with chronic low back pain. J Rehabil Med 2009;41:620-5.

14. Sullivan M, Tanzer M, Stanish W, et al. Psychological determinants of problematic outcomes following total knee arthroplasty. Pain 2009;143:123-9.

15. Buenaver LF, Edwards RR, Smith MT, Gramling SE, Haythornthwaite JA. Catastrophizing and pain-coping in young adults: Associations with depressive symptoms and headache pain. J Pain 2008;9:311-9.

16. Sullivan MJL, Thorn B, Rodgers W, Ward C. A path model of psychological antecedents of pain experience: Clinical and experimental findings. Clin J Pain 2004;20:164-73.

17. Crombez G, Eccleston C, Baeyens F, van Houdenhove, van den Broeck A. Attention to chronic pain is dependent upon pain-related fear. J Psychosom Res 1999;47:403-10.

18. Rief W, Barsky AJ. Psychobiological perspectives on somatoform disorders. Psychoneuroendocrinology 2005;30:996-1002.

19. Devoulyte K, Sullivan MJL. Pain catastrophizing and symptom severity during upper respiratory tract illness. Clin J Pain 2003;19:125-33.

20. Wickramasekera IE. Somatization. Concepts, data, and predictions from the high risk model of threat perception. J Nerv Ment Dis $1995 ; 183: 15-23$.

21. Lieb R, Meinlschmidt G, Araya R. Epidemiology of the association between somatoform disorders and anxiety and depressive disorders: An update. Psychosom Med 2007;69:860-3.

22. McDermid AJ, Rollman GB, McGain GA. Generalized hypervigilance in fibromyalgia: Evidence of perceptual amplification. Pain 1996;66:133-44.

23. Hollins M, Harper D, Gallagher S, et al. Perceived intensity and unpleasantness of cutaneous and auditory stimuli: An evaluation of the generalized hypervigilance hypothesis. Pain 2009;141:215-21.

24. Roelofs J, Peters ML, van der Zijden M, Vlaeyen JWS. Does fear of pain moderate the effects of sensory focusing and distraction on cold pressor pain in pain-free individuals? J Pain 2004;5:250-6.

25. George SZ, Dannecker EA, Robinson ME. Fear of pain, not pain catastrophizing, predicts acute pain intensity, but neither factor predicts tolerance or blood pressure reactivity: An experimental investigation in pain-free individuals. Eur J Pain 2006;10:457-65.

26. Hirsh AT, George SZ, Bialosky JE, Robinson ME. Fear of pain, pain catastrophizing, and acute pain perception: Relative prediction and timing of assessment. J Pain 2008;9:806-12.

27. Crombez G, Eccleston C, Van den Broeck A, Goubert L, Van Houdenhove B. Hypervigilance to pain in fibromyalgia:
The mediating role of pain intensity and catastrophic thinking about pain. Clin J Pain 2004;20:98-102.

28. Roelofs J, Peters ML, Vlaeyen JW. Selective attention for pain-related information in healthy individuals: The role of pain and fear. Eur J Pain 2002;6:331-9.

29. Ellenbogen MA, Schwartzman AE, Stewart J, Walker CD. Stress and selective attention: The interplay of mood, cortisol levels, and emotional information processing. Psychophysiology 2002;39:723-32.

30. van Honk J, Tuiten A, van den Hout M, et al. Baseline salivary cortisol levels and preconscious selective attention for threat. A pilot study. Psychoneuroendocrinology 1998;23:741-7.

31. van Honk J, Tuiten A, van den Hout M, et al. Conscious and preconscious selective attention to social threat: Different neuroendocrine response patterns. Psychoneuroendocrinology 2000;25:577-91.

32. Putman P, Hermans EJ, Koppeschaar H, van Schijndel A, van Honk J. A single administration of cortisol acutely reduces preconscious attention for fear in anxious young men. Psychoneuroendocrinology 2007;32:793-802.

33. Soravia LM, Heinrichs M, Aerni A, et al. Glucocorticoids reduce phobic fear in humans. Proc Natl Acad Sci U S A 2006;103:5585-90.

34. Buchanan TW, Brechtel A, Sollers JJ, Lovallo WR. Exogenous cortisol exerts effects on the startle reflex independent of emotional modulation. Pharmacol Biochem Behav 2001;68:203-10.

35. McCracken LM. 'Attention' to pain in persons with chronic pain: A behavioral approach. Behav Res Ther 1997;28:271-84.

36. McCracken LM, Zayfert C, Gross RT. The Pain Anxiety Symptoms Scale: Development and validation of a scale to measure fear of pain. Pain 1992;50:67-73.

37. Sullivan MJL, Bishop S, Pivik J. The pain catastrophizing scale: Development and validation. Psychol Assess 1995;7:527-32.

38. Tousignant-Laflamme Y, Marchand S. Excitatory and inhibitory pain mechanisms during the menstrual cycle in healthy women. Pain 2009;146:47-55.

39. Sherman JJ, LeResche L. Does experimental pain response vary across the menstrual cycle? A methodological review. Am J Physiol Regul Integr Comp Physiol 2006;291:R245-R256.

40. Bajaj P, Arendt-Nielsen L, Bajaj P, Madsen H. Sensory changes during the ovulatory phase of the menstrual cycle in healthy women. Eur J Pain 2001;5:135-44.

41. Hansen AM, Garde AH, Persson R. Sources of biological and methodological variation in salivary cortisol and their impact on measurement among healthy adults: A review. Scand J Clin Lab Invest 2008;68:448-58.

42. Kudielka BM, Kirschbaum C. Awakening cortisol responses are influenced by health status and awakening time but not by menstrual cycle phase. Psychoneuroendocrinology 2003;28:35-47.

43. Simunkova K, Starka L, Hill M, Kriz L, Hampl R, Vondra K. Comparison of total and salivary cortisol in a low-dose ACTH (Synacthen) test: Influence of three-month oral contraceptives administration to healthy women. Physiol Res 2008;57(Suppl 1):S193-S199.

44. Bouma EM, Riese H, Ormel J, Verhulst FC, Oldehinkel AJ. Adolescents' cortisol responses to awakening and social stress; effects of gender, menstrual phase and oral contraceptives. The TRAILS study. Psychoneuroendocrinology 2009;34:884-93.

45. McWilliams LA, Asmundson GJ. The relationship of adult attachment dimensions to pain-related fear, hypervigilance, and catastrophizing. Pain 2007;127:27-34.

46. Walter B, Hampe D, Wild J, Vaitl D. Die Erfassung der Angst vor Schmerzen: Eine modifizierte deutsche Version der Pain Anxiety Symptom Scale (PASS-D). Der Schmerz 2002;15(Suppl 1):83.

47. Meyer K, Sprott H, Mannion AF. Cross-cultural adaptation, reliability, and validity of the German version of the Pain Catastrophizing Scale. J Psychosom Res 2008;64:469-78.

48. Roelofs J, Peters ML, Muris P, Vlaeyen JWS. Dutch version of the Pain Vigilance and Awareness Questionnaire: Validity and reliability in a pain-free population. Behav Res Ther 2002;40:1081-90.

49. Keogh E, Ellery D, Hunt C, Hannent I. Selective attentional bias for pain-related stimuli amongst pain fearful individuals. Pain 2001;91:91-100.

50. Amthauer R, Brocke B, Liepmann D, Beauducel A. Intelligenz-Struktur-Test $2000 \mathrm{R}$ (2, revised edition). Göttingen: Hogrefe, 2001. 
51. Lautenbacher S, Huber C, Kunz M, et al. Hypervigilance as predictor of postoperative acute pain: Its predictive potency compared to experimental pain sensitivity, cortisol reactivity and affective state. Clin J Pain 2009;25:92-100.

52. Rief W, Hiller W, Heuser J. SOMS - Das Screening für Somatoforme Störungen (Manual zum Fragebogen). Bern: Huber, 1997.

53. Laux L, Glanzmann P, Schaffner P, Spielberger CD. Das State-Trait-Angstinventar (Testmappe mit Handanweisung, Fragebogen STAI-G Form X 1 und Fragebogen STAI-G Form X 2). Weinheim: Beltz, 1981.

54. Hautzinger M, Bailer M. Allgemeine Depressionsskala ADS. Weinheim: Beltz, 1992.

55. Pruessner JC, Wolf OT, Hellhammer DH, et al. Free cortisol levels after awakening: A reliable biological marker for the assessment of adrenocortical activity. Life Sci 1997;61:2539-49.

56. Kirschbaum C, Hellhammer DH. Salivary cortisol in psychoneuroendocrine research: Recent developments and applications. Psychoneuroendocrinology 1994;19:313-3.

57. Raff H. Utility of salivary cortisol measurements in Cushing's syndrome and adrenal insufficiency. J Clin Endocrinol Metab 2009; $94: 3647-55$.

58. Pruessner JC, Hellhammer DH, Kirschbaum C. Burnout, perceived stress, and cortisol responses to awakening. Psychosom Med 1999;61:197-204.

59. Margraf J. Mini-DIPS. Diagnostisches Kurz-Interview bei psychischen Störungen. Berlin: Springer, 1994.

60. Bollen KA, Long JS. Testing structural equation models. London: SAGE Publications, 1993.

61. Backhaus K, Erichson B, Plinke W, Weiber R. Multivariate Analysemethoden. Eine anwendungsorientierte Einführung (11, revised edition). Berlin: Springer, 2006:337-424.

62. Roelofs J, Peters ML, van der Zijden M, Thielen FG, Vlaeyen JW. Selective attention and avoidance of pain-related stimuli: A dot-probe evaluation in a pain-free population. J Pain 2003;4:322-8.

63. Asmundson GJ, Wright KD, Hadjistavropoulos HD. Hypervigilance and attentional fixedness in chronic musculoskeletal pain:
Consistency of findings across modified stroop and dot-probe tasks. J Pain 2005;6:497-506.

64. Asmundson GJ, Hadjistavropoulos HD. Is high fear of pain associated with attentional biases for pain-related or general threat? A categorical reanalysis. J Pain 2007;8:11-8.

65. Keogh E, Thompson T, Hannent I. Selective attentional bias, conscious awareness and the fear of pain. Pain 2003;104:85-91.

66. Sullivan MJL, Thorn, B, Haythornthwaite JA, et al. Theoretical perspectives on the relation between catastrophizing and pain. Clin J Pain 2001;17:52-64.

67. Geisser ME, Robinson ME, Keefe FJ, Weiner ML. Catastrophizing, depression and the sensory, affective and evaluative aspects of chronic pain. Pain 1994;59:79-83.

68. Haaga DA. Catastrophizing, confounds, and depression: A comment on Sullivan and D'Eon (1990). J Abnorm Psychol 1992;101:206-7.

69. Jensen MP, Turner JA, Romano JM, Karoly P. Coping with chronic pain: A critical review of the literature. Pain 1991;47:249-83.

70. Osman A, Barrios FX, Gutierrez PM, Kopper BA, Merrifield T, Grittmann L. The Pain Catastrophizing Scale: Further psychometric evaluation with adult samples. J Behav Med 2000;23:351-65.

71. Eccleston C, Crombez G, Aldrich S, Stannard C. Attention and somatic awareness in chronic pain. Pain 1997;72:209-15.

72. Janssen SA. Negative affect and sensitization to pain. Scand J Psychol 2002;43:131-7.

73. Meredith PJ, Strong J, Feeney JA. Evidence of a relationship between adult attachment variables and appraisals of chronic pain. Pain Res Manage 2005;10:191-200.

74. Pavlin DJ, Sullivan MJ, Freund PR, Roesen K. Catastrophizing: A risk factor for postsurgical pain. Clin J Pain 2005;21:83-90.

75. Boersma K, Linton SJ. Psychological processes underlying the development of a chronic pain problem: A prospective study of the relationship between profiles of psychological variables in the fear-avoidance model and disability. Clin J Pain 2006;22:160-6. 


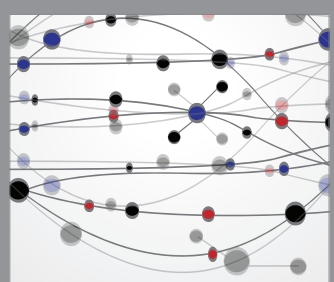

The Scientific World Journal
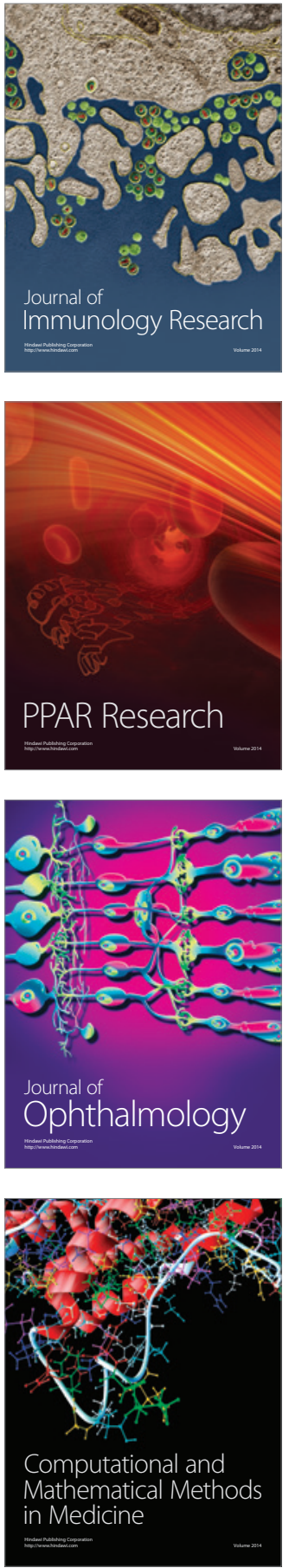

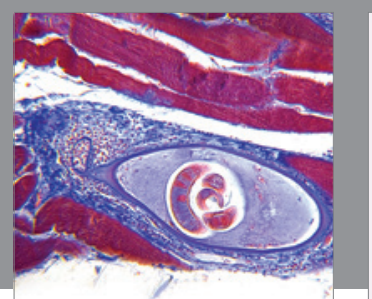

Gastroenterology Research and Practice

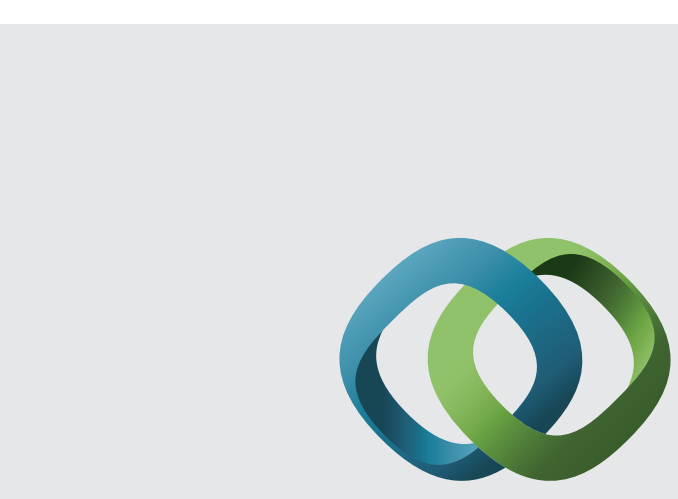

\section{Hindawi}

Submit your manuscripts at

http://www.hindawi.com
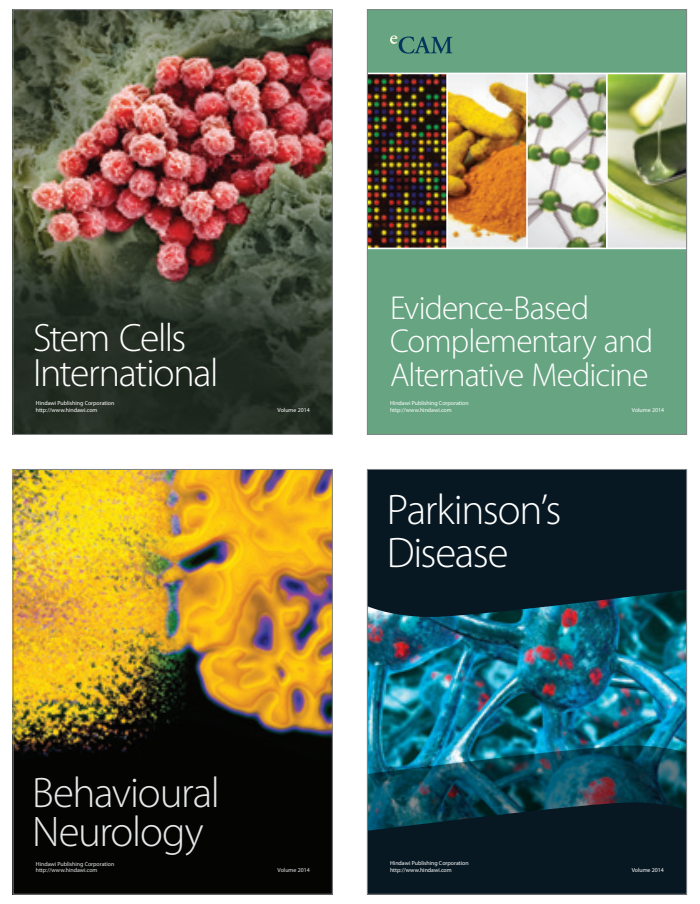
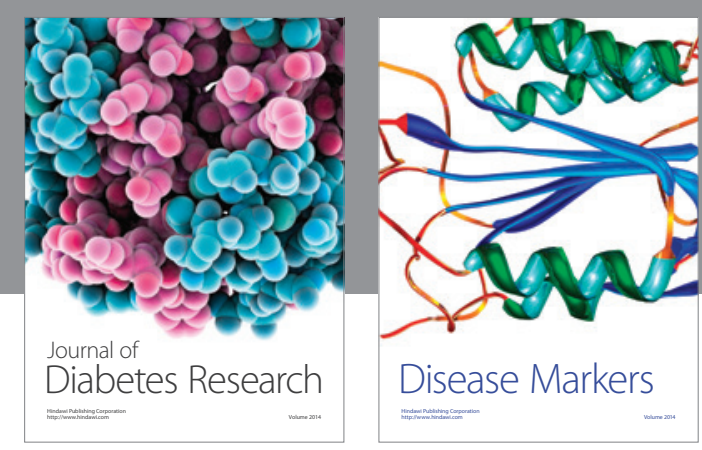

Disease Markers
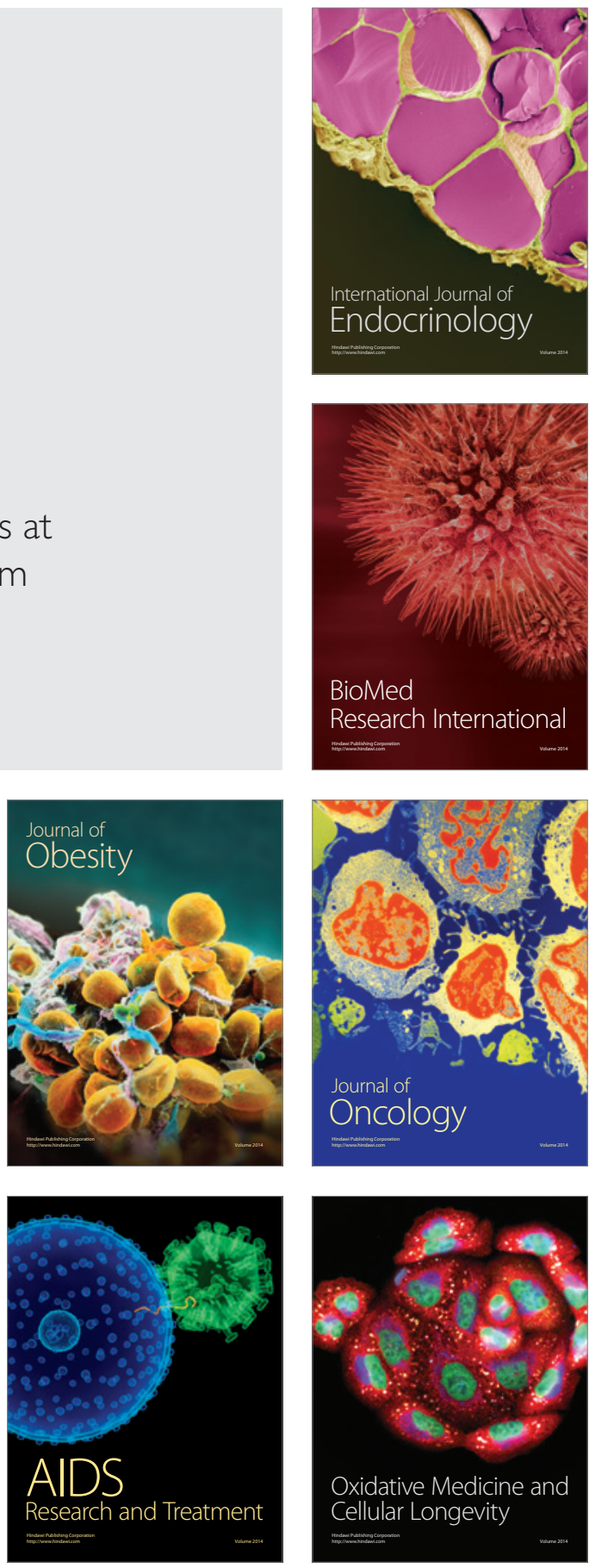